РАЗОВ Павел Викторович - доктор социологических наук, доцент; профессор департамента социологии, истории и философии Финансового университета при Правительстве РФ (125993, Россия, 2. Москва, Ленинградский пр-кт, 49; pvrazov@fa.ru)

ШТЕПА Сергей Евгеньевич - магистр факультета социологии и политологии Финансового университета при Правительстве РФ (125993, Россия, г. Москва, Ленинградский пр-кт, 49; SEShtepa@ gmail.com)

\title{
СОЦИАЛЬНЫЕ РИСКИ КАК КЛЮЧЕВОЙ АСПЕКТ ПРОЦЕССА СОЦИАЛИЗАЦИИ
}

Аннотация. В условиях современного российского общества, которое подвержено движению и постоянным изменениям, растет число социальных рисков и областей их возникновения. Вопрос изучения рисков сейчас актуален в большей степени, чем раньше. В связи с этим можно сделать вывод о значимости процесса социализации, поскольку именно в нем подрастающее поколение начинает знакомство с обществом риска.

Ключевые слова: социальные риски, общество риска, социализация

$\mathrm{O}$ пираясь на классическое понимание риска в современной социологии, можно сказать, что под риском подразумевается какая-либо деятельность, результат которой не определен.

В доиндустриальный период понятие риска в обществе характеризуется беспомощностью человека перед силами природы, которая на ранних этапах развития общества всегда одерживала верх. То есть, данная среда приобрела враждебный статус, поскольку таила в себе болезни, эпидемии, землетрясения, засухи.

В постиндустриальный период взгляд на риск изменился и стал связываться с личной ответственностью человека и общества в целом.

Современный подход рассматривает риск как результат человеческой деятельности, вследствие чего были сформированы определенные теоретические подходы к его осмыслению.

Здесь можно выделить научно-когнитивный подход, суть которого заключается в том, что риск является следствием любой ситуации как объективное явление, которое происходит вследствие вероятностей и их последствий; социально-конструктивистский подход, который подразумевает само явление возникновения риска как следствие экономических, политических и правовых дисфункций, являющихся следствием формирования среды, связанной с риском; и социокультурный, который подходит к изучению риска сквозь призму социально-психологических особенностей людей, которые оказывают влияние и принимают решения в области политики, культуры, экономики и т.д.

Положение дел общества и его основных социальных институтов не дает возможности полноценно противостоять социальным рискам, а, наоборот, укрепляет уже существующие рискогенные зоны и способствует образованию новых через институты общества. Риск прогрессирует в сущностную характеристику функционирования сфер общества, имеющих огромную значимость для жизни.

Зоной с наибольшим числом рисков и, соответственно, наиболее насыщенными со стороны социальной рискогенности являются такие институты, как духовный, экономический, политический, семейно-брачный, правовой. Данные институты с имеющимися в них рисками серьезно влияют на безопасность российского общества и государства в целом. Как правило, речь идет о 
таких рисках, как социально-правовые, социально-политические, социальноэкономические.

Одной из наиболее изученных теорий, обладающей собственными традициями в социологии, можно считать теорию социализации. Данная теория берет свои корни с времен, когда социология только формировалась как научная отрасль. В силу накопленных знаний социология имеет мощную методологическую базу для исследования процесса социализации, в которой, собственно, и коренятся различные социальные риски. Процесс социализации происходит через понятие адаптации [Парсонс 1993], в ходе которой происходит приспособление к новым условиям социальной реальности или среды. Все это происходит в рамках структурного функционализма и раскрывает возможные подводные камни в виде социальных рисков при процессе адаптации.

Но в современных реалиях общество благодаря условиям неопределенности и рискогенности социального пространства развивается настолько быстро, что сохранение общества как единого целого невозможно. Проблема приобретает большие масштабы, и социальные риски растут вместе с ориентацией на общество риска.

А.И. Ковалева предлагает концепцию социализационной нормы, которая соответствует условиям современного общества. Под данной концепцией подразумевается успешная социализация, благодаря которой возможно дальнейшее развитие и прогресс в области культурных ценностей [Ковалева 2003: 109]. Именно через процесс социализации проходит молодежь, еще не встречавшая многочисленные социальные риски, но в дальнейшем именно она будет представлять общество и отражать все его сформировавшиеся ценности и устои.

Огромное влияние на социальные нормы оказывают такие факторы, как терроризм, бедность, безработица, массовая культура, загрязнение окружающей среды. Все эти факторы так или иначе относятся к социальным рискам. Также они влияют и на обстановку в стране в целом [Абдикерова 2009: 42].

Появляется такой термин, как «интерпретирующее воспроизводство», который отражает принадлежность детей и молодежи к процессу социализации. Именно люди данных возрастов не только восприимчивы к усвоению общественных норм и ценностей, но и вносят вклад в их изменение [Мид 1988]. Как отмечает Ковалева, отклоняющаяся социализация, рассматриваемая как широкое явление, позволяет выделить в ней такие подтипы, как девиантное и делинквентное поведение.

Ввиду происходящих изменений в социуме и социализационном процессе выделяется концепция М. Мид, которая приводится в ее работе «Культура и мир детства». В ней выделяется три типа культур: постфигуративный, кофигуративный и префигуративный [Мид 1988]. Данные типы культур различаются в зависимости от характера взаимодействия между поколениями в процессе социализации. Постфигуративный тип культуры относится к передаче накопленных знаний предыдущими поколениями в ходе социализации, поэтому изменения между поколениями минимальны; кофигуративный представляет собой заимствование поведения у сверстников независимо от возраста; префигуративный тип связан с передачей знаний старшим поколениям от подрастающего, которое более восприимчиво к новшествам и технологиям.

Каждый тип по-своему проходит социализацию и имеет свои плюсы и минусы. Также для каждого типа культуры характерны и свои социальные риски, которые характерны для свойственной ему культуры и преобладают в ней.

В рамках деятельностного подхода процесс социализации рассматривается как двусторонний процесс. Суть данного процесса заключается в усвоении социального опыта, который в дальнейшем превращается в ценности, уста- 
новки и ориентации. В совокупности все действия приносят плоды на этапах социализации, и общество получает людей со свойственным данному обществу уровнем сознания и поведения.

Но изменения все-таки происходят. Каждое поколение на протяжении жизни проходит через изменения ценностно-нормативной системы общества. Такие факторы, как опыт, ценности, нормы и образцы поведения, оказывают влияние на облик общества. Механизм социокультурной динамики отражает специфику данного явления как для каждого поколения, так и для общества в целом [Элиас 2001: 11].

В социологической науке имеет место изучение определенных социальных рисков. Так, Ю.А. Зубок проводила изучение поведения молодежи в обществе риска, где вследствие кризиса и нестабильности возникли и накопились проблемы в форме устойчивого состояния риска. В частности, данные проблемы отражаются и на развитии молодежи.

Как правило, в качестве источника негативных явлений в молодежной среде выделяют кризис институтов социализации, который образовался в эпоху перемен - в 1990-х гг. Данный кризис является источником создания и укрепления социализационных рисков. Впоследствии образуются негативные явления в подростковой и молодежной среде, которые отражаются на духовно-нравственном характере, физическом развитии молодежи и т.д. Это очень важно, поскольку создает опасность для общества и, в частности, для молодого поколения, которое является будущим каждого общества.

Современные темпы развития молодежи отражают модернизацию современного общества. Ускорение темпа жизни приводит и к увеличению социальных рисков, неопределенности в развитии молодежи.

Здесь можно отметить, что причиной возникновения риска будет служить ситуация, которая ведет к различным вариантам исхода и последствиям, которые вполне возможны на данном этапе. Иными словами, причиной любого риска будет служить ситуация неопределенности.

Если брать социальную жизнедеятельность молодежи, то практически любая деятельность по прояснению ситуации сопряжена с рисками. Молодежь является наиболее рискогенным слоем общества, поскольку в силу юного возраста не обладает должным опытом и знаниями.

Как правило, риски возникают из-за противоречий между возможностями развития для молодежи и социальными условиями. Такие противоречия негативно сказываются на взаимодействиях в молодежной среде и обществе в целом и накладывают свой отпечаток на социализацию.

В связи с этим взаимодействие предыдущих поколений и молодежи отличается непредсказуемостью и неопределенностью, что пагубно влияет на состояние молодежи, обостряя ее неуверенность в окружающем мире. Дальше по цепочке подрываются основы безопасности, личности, группы и общества. А любое движение в поисках благ и новых возможностей сопровождается риском и вероятностью неудачи.

На данный момент наблюдается нехватка поддержки молодежи со стороны социальных институтов, что ведет к разрыву былых связей и принятию молодежью самостоятельных решений в ситуациях неопределенности и риска. Не всегда выбранное решение является верным, что отражается на дальнейшем опыте молодежи.

Все социальные возможности молодежи зависят от ее расположения в социальной структуре общества. То есть, они зависят от сил, находящихся вне их контроля. В их число входят: образование, условия рынка труда, нормы регуляторов их жизнедеятельности. В какой-то степени беспомощность при выборе 
жизненного пути в обществе риска приводит возрастанию классового неравенства.

Следует отметить, что основное противоречие общества риска связано с ограничениями в реализации молодежи и вариантами самореализации. Лишение привычных форм социальной защиты приводит к тому, что молодежь остается наедине с обществом риска, где риск приобретает образ жизни.

Необходимо предпринимать все возможные усилия, чтобы защитить молодежь от рискогенных ситуаций, выработать программу по подготовке детей к взрослой жизни, формируя культурные ценности на ранних этапах взросления. В частности, следует проработать все пути минимизации рисков в молодости, предложить облегченные условия в рискогенных сферах.

Разработав программу социализации молодежи, в будущем можно рассчитывать на хорошее поколение людей, которое передаст свои навыки выживания в обществе риска молодому поколению, минимизируя их рискогенные ситуации.

Люди, попавшие под действие рисков, будут создавать предпосылки для социального протеста, что может негативно сказаться на обстановке в стране. А самое страшное, что это может использоваться деструктивными политическими силами с целью дестабилизации обстановки в стране.

\section{Список литературы}

Абдикерова Г.О. 2009. Евразийская ментальность как основа создания интегральной модели социализации личности. - Социс. Социологические исследования. № 9. С. 42-47.

Ковалева А.И. 2003. Концепция социализации молодежи: нормы, отклонения, социализационная траектория. - Социс. Социологические исследования. № 1 . С. $109-115$.

Мид М. 1988. Культура и мир детства. М.: Наука. 429 с.

Парсонс Т. 1993. Понятие общества: компоненты и их взаимоотношения. THESIS. Вып. 2. С. 94-122.

Элиас Н. 2001. Общество индивидов (пер. с нем.). М.: Праксис. 331 с.

RAZOV Pavel Viktorovich, Dr.Sci. (Soc.), Associate Professor; Professor of the Department of Sociology, History and Philosophy, Financial University under the Government of the Russian Federation (49 Leningradsky Ave, Moscow, GSP-3, Russia, 125993; pvrazov@fa.ru)

SHTEPA Sergei Evgen'evich, M.A. student of the Faculty of Sociology and Political Science, Financial University under the Government of the Russian Federation (49 Leningradsky Ave, Moscow, GSP-3, Russia, 125993; SEShtepa@gmail. com)

\section{SOCIAL RISKS AS A KEY ASPECT OF THE SOCIALIZATION PROCESS}

Abstract. In the conditions of modern Russian society, which is subjected to movement and constant changes, the number of social risks and areas of their occurrence is growing. The question of studying risks is now more relevant than before. In connection with this, it is possible to draw a conclusion about the significance of the socialization process, since namely in it the younger generation begins their acquaintance with the risk society.

Keywords: social risks, risk society, socialization 